\title{
Status of Solid Waste Management Service in Metu Town, South-Western Ethiopia
}

\author{
Biruk Gobena ${ }^{1 *}$, Yohannis Fetene ${ }^{1}$ and Gezahegne Seyoum Gebremedhin ${ }^{2}$ \\ ${ }^{1}$ Ethiopian Environment and Forest Research Institute, Environmental Pollution Management Research Directorate, Ethiopia \\ ${ }^{2}$ Ethiopian Environment and Forest Research Institute, Socio-economics, Policy, Extension and Gender Research Directorate, Ethiopia
}

Submission: July 23, 2020; Published: August 12, 2020

*Corresponding author: Biruk Gobena, Ethiopian Environment and Forest Research Institute, Environmental Pollution Management Research Directorate, Ethiopia

\begin{abstract}
Municipal solid waste management (MSWM) services in most cities and towns are already over-burdened, as cities and municipalities cannot cope with the speeded pace of waste production provided that inadequate financial capacity, insufficient manpower, and facilities. A cross-sectional study was conducted to assess the status of municipal solid waste management service of Metu town using a questionnaire and observational checklist. A total of 252 households (HHs) and 65 commercial and institutional establishments (CIs) were included in this study. Data was analyzed using Statistical Package for Social Sciences (SPSS) software version 20. Accordingly, among 317 study participants, $213(67.1 \%)$ females and $104(32.9 \%)$ males with a mean age of 36.45 have participated. Concerning solid waste collection frequency, more than $35 \%$ of $\mathrm{HHs}$ and $70 \%$ of CIs get the service from Micro and Small Enterprise (MSE) with irregular interval whereas; about $56 \%$ of $\mathrm{HHs}$ and $15 \%$ of CIs responded that they get the service from MSE in more than 30 days. The solid waste disposal site currently used by Metu town is an open field that was found inadequate and poorly handled. Hence, about $64.7 \% \mathrm{HHs}$ and $68.29 \%$ of CIs and $31.4 \% \mathrm{HHs}$ and $17.04 \%$ of CIs responded that they were slightly satisfied and not at all satisfied, respectively. None of the customers responded that they are completely satisfied with both municipal and MSE services. The solid waste management service in Metu town is very weak and by far below standard. Therefore, the government should be engaged in redesigning a strategy of delivering modern, high-quality solid waste management to build an acceptable and satisfactory level of SWM service..
\end{abstract}

Keywords: Solid waste management; Service delivery; Client satisfaction level; Solid waste disposal

Abbreviations: SWM: Solid Waste Management; MSWM: Municipal Solid Waste Management; CI: Commercials and Institutions; HH: Households; MSE: Micro Scale Enterprises; ETB: Ethiopian Birr; SW: Solid Waste; UNEP: United Nations Environment Programme

\section{Introduction}

The solid waste production growth in quantity and complexity is posing extra danger to the environment. It is estimated that about 1.7 to 1.9 billion metric tons of MSW is generated worldwide. The percentage of waste collection rate, the collected waste disposed of through uncontrolled landfill, and the collected waste processed through perilous and informal recycling is lower than 70 , more than 50 , and about 15 per cent, respectively [1]. In most developing countries open dumps and open burning are continued to be used as the primary MSW disposal method [2].

One of the basic factors for poor waste management in developing countries is a service delivery system for which local administration bodies are usually responsible. Although the most important task of these authorities is to manage the waste properly, municipal services in most cities and towns are already over-burdened and cannot cope with the growing demand owing to inadequate financial capacity, insufficient manpower, and facilities [3]. "In developing countries, 20-50 per cent of the recurring budget of municipalities is often spent on solid waste management, although often only 50 per cent of the urban population is covered by these services. In low-income countries, collection alone drains 80-90 per cent of total waste management budgets" [4]. Around $\$ 48$ billion is spent by developing countries on municipal solid waste management and it is envisaged that this amount needs to double to repair the commonly encountered service delivery gap [5]. Moreover, considering the projected increase in municipal solid waste generation due to an increase in population and economic growth, financing needs may grow to $\$ 150$ million yearly by 2025 [6].

In many cities of developing countries, the waste collection rates remain low and the quality of collection services are poor. While, waste collection services are generally non-existent in poorer neighborhoods such as slums [4]. One-thirds to two- 
thirds of the municipal solid waste generated in the developing world is dumped haphazardly on streets or in drains, thus causing floods, serves as breeding grounds for insects and rodents which further facilitate the spread of diseases [7]. The collected waste is generally dumped on land in uncontrolled manner where they may be burnt. Such uncontrolled and inadequate waste disposal creates serious environmental problems, affects human and animal health, and causes serious financial and socio-economic losses. This condition can get worse by increasing urban population growth, high urbanization, economic growth rates, poverty, weak governmental institutions, lack of implementation and enforcement of policies, and insufficient public finances [8]. Hence, this study has tried to assess the municipal solid waste management service delivery system in contrast to the client satisfaction level of Metu town, southwestern Ethiopia. Plus it has shown the bottleneck of the service delivery system of municipal solid waste management in the town.

\section{Materials and Methods}

The cross-sectional study design was conducted to assess the municipal solid waste management service delivery system of Metu town, southwestern Ethiopia. Metu town is located $542 \mathrm{Km}$ South West of Addis Ababa which has a latitude of $8^{\circ} 18^{\prime}$ $0 " \mathrm{~N}$ and longitude $35^{\circ} 34^{\prime} 60^{\prime \prime} \mathrm{E}$ at an altitude of 1605 meters (Figure 1). The town is divided into 3 administrative units called kebeles in which 9,753 households were residing as Metu town administration has reported during the study period.

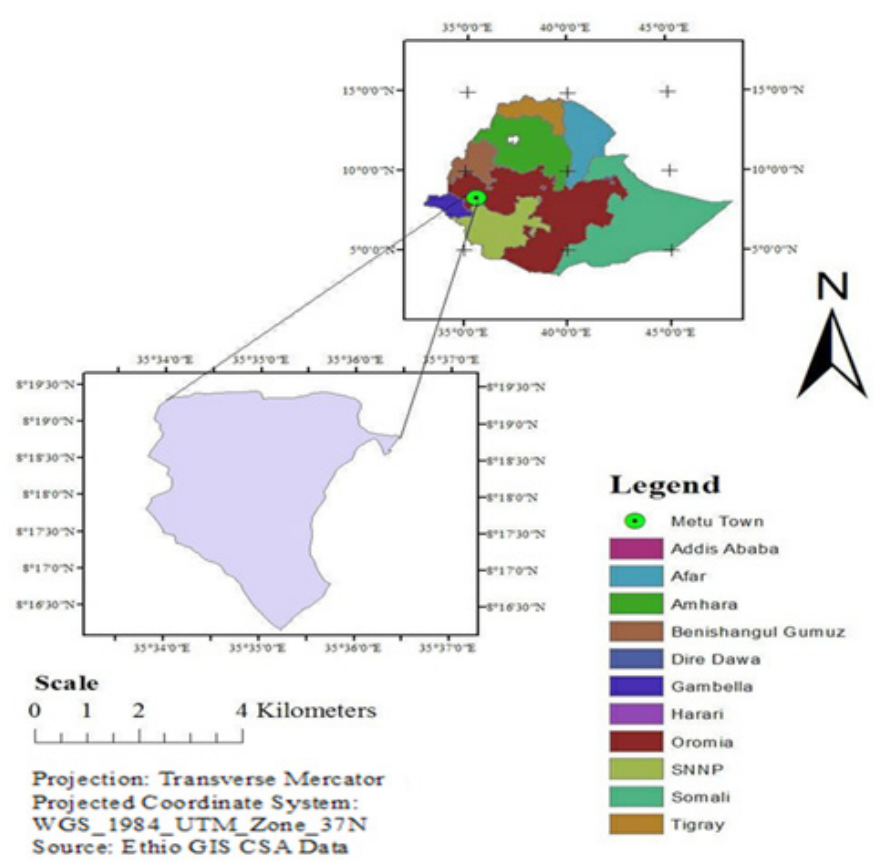

Figure 1: Study site: Metu town, South Western Ethiopia.

The sample size was determined using a single population proportion formula at a $90 \%$ confidence interval and 4.62 margin of error. Accordingly, the data were collected from 317 participants ( 252 from HHs and 65 from CIs) using a pretested structured questionnaire by well trained and experienced data collectors under the close supervision of investigators. Systematic random sampling techniques were employed to determine the number of samples per kebele and sector/ establishments. one person was interviewed from each HHs as well as CIs. All employees working in solid waste management department and all workers of MSE who worked in solid waste collection and management service in the town were also interviewed using a structured questionnaire to assess the solid waste management service delivery system of the town. Finally, the collected data was analyzed using Statistical
Package for Social Sciences (SPSS) software version 20.

\section{Results and Discussion}

\section{Socio-demographic characteristics of the respondents}

A total of 252 households (HHs) and 65 commercial and institutional establishments (CIs) were included in this study. Among households' study participants, 213(67.1\%) were female and 104 (32.9\%) were males. . The majority of the study participants were found in the age range of 25-44 (73.8\%) with a mean of 36.45. Regarding the occupational and educational status of respondents, $143(45.1 \%)$ of the respondents were government workers, and $101(31.8 \%)$ of the participant were reported as they had grade 9-12 educational status (Figure 2). 


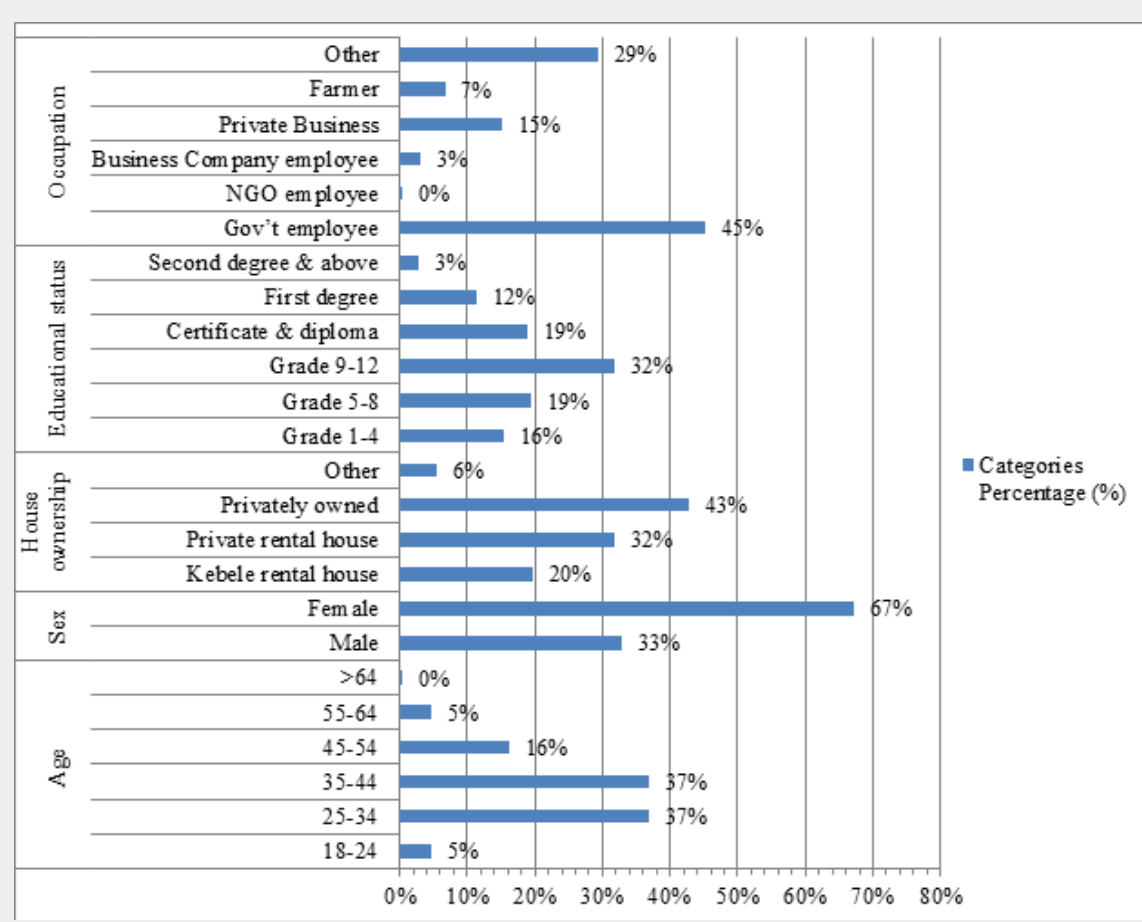

Figure 2: Socio-demographic characteristics of respondents in Metu town.

\section{Solid waste collection services status}

Door to door solid waste collection service in Metu town which is largely applied for the collection of solid waste from residential, commercial and institutional areas was provided by town municipality, micro and small scale enterprise (MSE) and informal sectors (daily labors). In Metu town there was one MSE at the time of survey which involves in delivery of solid waste collection service to the town residents, commercials and institutions. However, the service coverage is very low as it reaches a very small number of residents, commercials \& institutions.

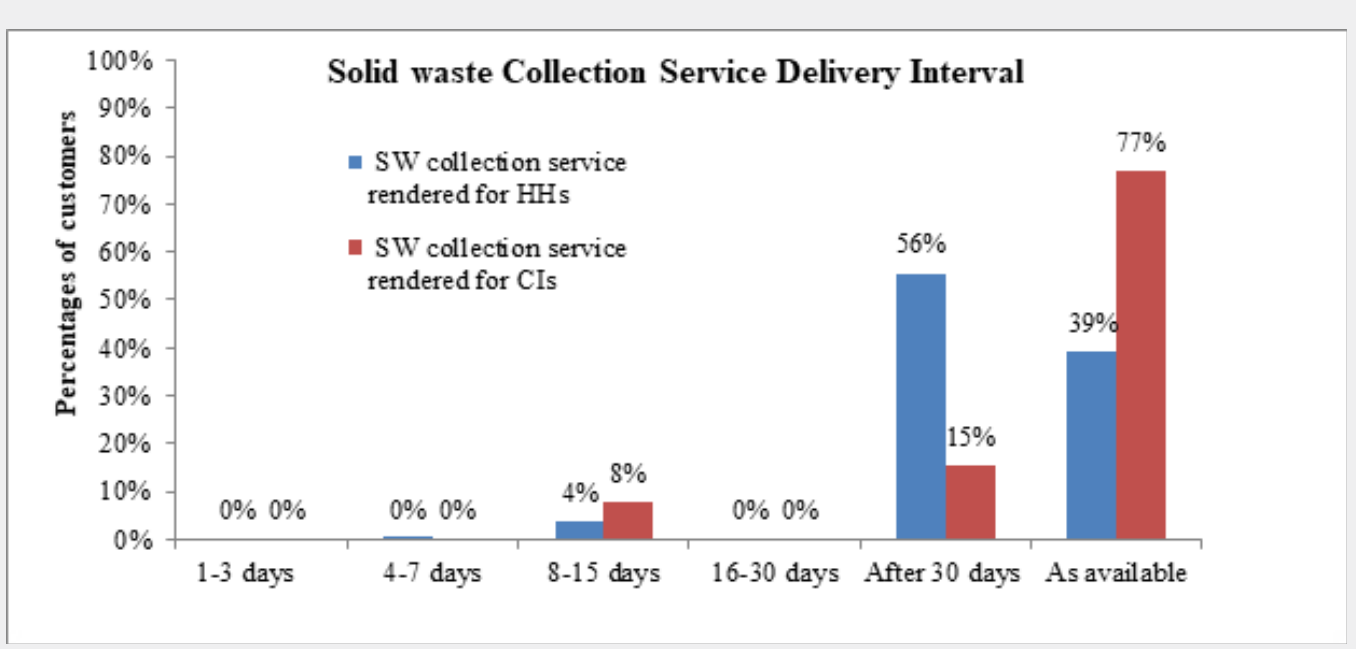

Figure 3: Solid waste collection Service delivery interval of MSE.

The efficiency of waste collection/management is determined by different factors, among them waste collection service delivery interval is one. Among study participants, more than 35\% of HHs and $70 \%$ of CIs get the service from MSE as with irregular interval. Almost, none of HHs and CIs is getting the solid waste collection service in less than a week from formal service provider's i.e. 
MSE and municipality (Figure $3 \& 4$ ). About 56\% of HHs and $15 \%$ of CIs responded that they get the service from MSE after 30 days interval whereas $27 \%$ of $\mathrm{HHs}$ and $32 \%$ of CIs were got the service from town municipality in more than 30 days (Figure 4). This data may be attributed to lack of internal roads for vehicle movement, lack of adequate functional vehicles and other waste collection facilities so that the municipality truck reaches only to very few residents who are situated in the central part of the town and along the main roads. In old towns like Metu, unplanned, haphazardly constructed, sprawling slums with narrow roads that are inaccessible to collection vehicles which may be among the problems that have led to ineffective waste management systems in town.

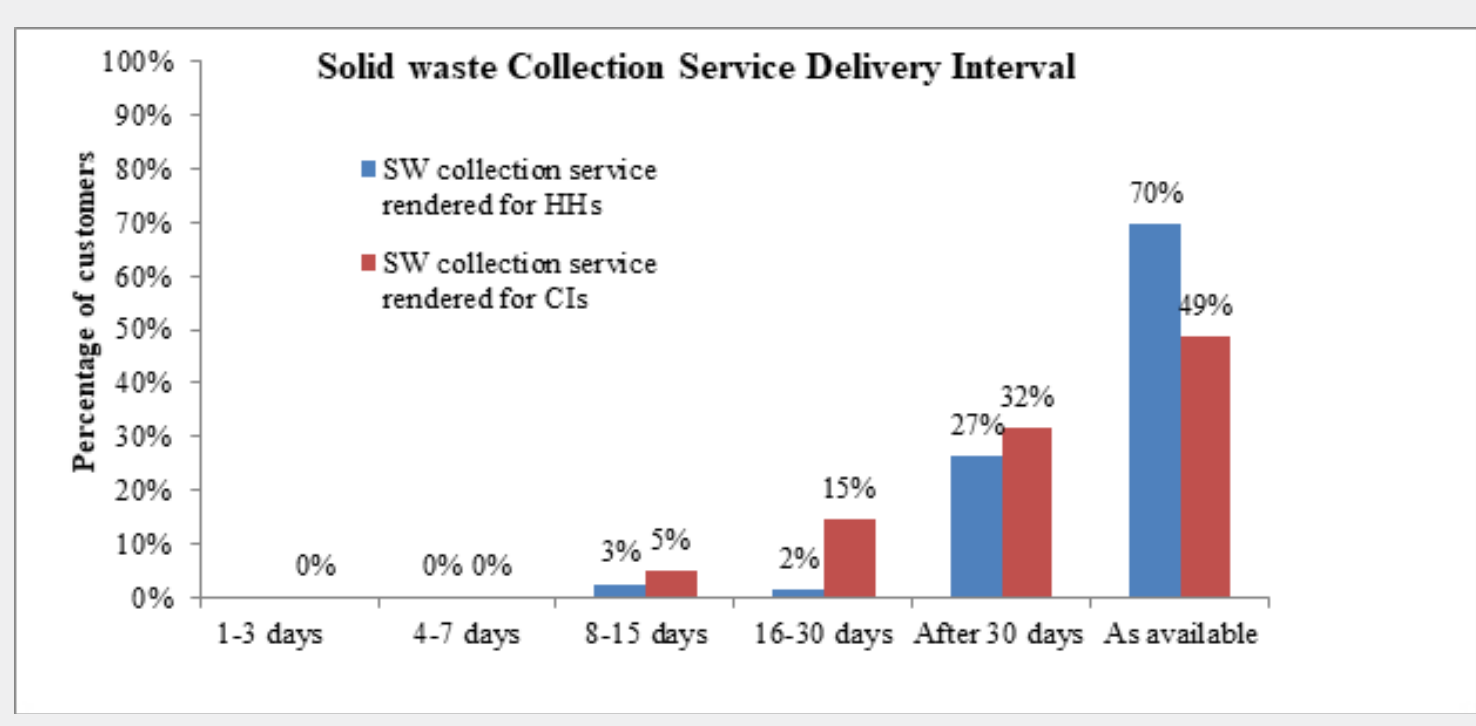

Figure 4: Solid waste collection Service delivery interval of the Municipality.

Another factor that determines waste collection management efficiency of a town is the payment rate of the service. More than $73 \%$ of HHs and $19 \%$ of CIs pay 10-20 ETB per week for the service provided by MSE in Metu town. About 26\% of HHs and 49\%HHs pay greater than 20ETB per week for MSE and informal sector, respectively (Table 1). Whereas, $42 \%$ of CIs and $17 \%$ CIs reported that they pay greater than 30ETB per week. Besides the customer's assessment, it was tried to interview the MSE leader of the town about their payment rate. Accordingly, they replied that they charge 10-30 birr per week from each served households and 20-100 birr from each served institutions and commercial sectors based on the amount of solid waste and distance from the disposal stations.

Table 1: Solid waste collection service expense of Metu town residents.

\begin{tabular}{|c|c|c|c|c|c|c|c|c|}
\hline \multirow{2}{*}{ Payment Rate per Week (ETB) } & \multicolumn{3}{|c|}{ Service from MSE } & \multicolumn{3}{c|}{ Service from Informal Sector } \\
\cline { 2 - 10 } & \multicolumn{2}{|c|}{ HHs } & \multicolumn{2}{c|}{ CIs } & \multicolumn{2}{c|}{ HHs } & \multicolumn{2}{c|}{ CIs } \\
\cline { 2 - 10 } & Frequency & $\%$ & Frequency & $\%$ & Frequency & $\%$ & Frequency & $\%$ \\
\hline $10-20$ & 139 & 73.54 & 10 & 19.23 & 60 & 50.85 & 16 & 39.03 \\
\hline $20-30$ & 32 & 16.93 & 20 & 38.46 & 46 & 38.98 & 18 & 43.9 \\
\hline $30-50$ & 18 & 9.52 & 14 & 26.92 & 12 & 10.17 & 3 & 7.32 \\
\hline $50-100$ & 0 & 0 & 8 & 15.38 & 0 & 0 & 4 & 9.76 \\
\hline Total & 189 & 100 & 52 & 100 & 118 & 100 & 41 & 100 \\
\hline
\end{tabular}

Solid waste management efficiency of the town also greatly depends on the capacity of the service provider. As reported by the head of Metu town Sanitation and Beautification department
(SWM department), though they are not functional, the town municipality has three open type trucks and one loading tractor for collection and transport of solid waste to final disposal site 
of the town. The type of truck used by the municipality is similar with the truck used in Bahir Dar town [9]; in Jigjiga town [10]; in Adama town [11,12]; in Hosanna town [13]; in Hawassa city [14]; in Kombolcha; in Jimma [15]; and also in Mekele city [16] to collect and transport solid waste to the disposal site.

The budget assigned for SWM has a great impact on the service delivery performance of the sector [17]. According to the head of the sanitation and beautification department, the only source of income for solid waste management activity was the municipality capital budget which is shared with other sectors. According to the department head report from the municipal budget, only some portion of it was being allocated to solid wasterelated purposes; rather the rest were assigned to other city's developmental activities.

From this finding, one could understand that the financial source of the sector was only a small portion of the municipal budget, which is crucial. Due to this, the sector faced a lack of capacity to purchase and provide the necessary facility to confirm effective SWM in the town. The department found the SWM service difficult to cope up with the increasing waste volume in the town. The government should solve grants for investment in green infrastructure through private sector involvement as well as by tapping into international/domestic green funds or financing mechanisms to solve such a financial gap.

\section{Solid waste disposal site management of the town}

Proper solid waste management requires proper disposal of wastes in a proper place [18]. The solid waste disposal site currently used by Metu town is an open field located at a distance of about $5 \mathrm{~km}$ from the center of the town. It is an agricultural area having an estimated area of 1000 square meters and a slope of $20 \%$. No extra modification was done to make the disposal site except the prepared open pit and its management was found inadequate and below the standard. At the same time, the site was also serving as a wastewater disposal site which intensifies the associated risks. As employees and head of the SWM department reported, the disposal site is selected by experts from the regional office. As confirmed through field observation, the management of Metu town solid waste disposal site is very poor because it does not have any fence that protects animals and people from entering into the site hence it can be dispersed to the surrounding villages by wind blow and runoff due slope (Figure 5). This poor disposal site management is expected to pollute and negatively affect the nearby environment, peoples living near the area, the nearby agricultural area, and animals, etc.

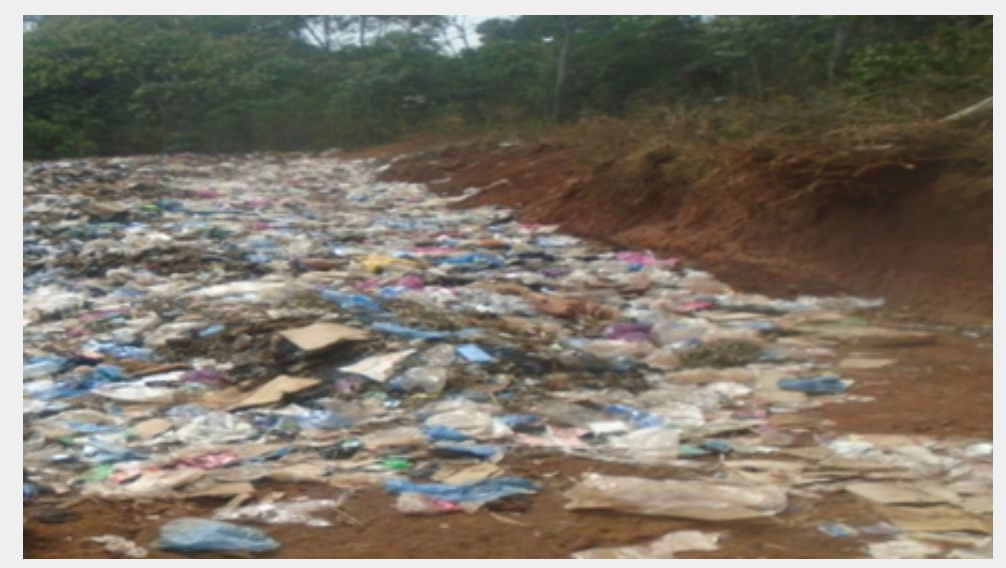

Figure 5: Metu town solid waste disposal site (Photo taken by researchers, February 13/2017).

The municipality should facilitate waste diversion such as reusing and recycling options as an alternative to reduce the amount of waste to be disposed of. If sanitary landfill cannot be feasible the current disposal method (open dumping) should be well managed in terms of fence, slope, and location. Sources of water supply and distance from it, the direction of the wind, distance from nearest residents, nearby farm areas and mainlands and distance that flies and rodents can travel from disposal site to the living area, the slope of the land, future expansion plan of the city should be taken in consideration in selecting a site for open land disposal the fact that these points are missed in siting solid disposal site of Metu town. Although the common solid disposal methods such as open-burning, open dumping, and nonsanitary landfill can still be used as disposal methods, they are not environmentally friendly and recommended.

\section{Client satisfaction towards SWM service in the town}

In Ethiopia, SWM service is among the services provided mainly by the government. In some towns of the country, MSE provides the service with irregular and unfair prices. Other 
than this the customers will use daily laborers to dump outside of their compound. Whatever the community will use for the specified service, the government has a responsibility to assure the required efficiency of solid waste management in the country. Hence this study has tried to measure the satisfaction level of the customers to solid waste management service they are receiving.

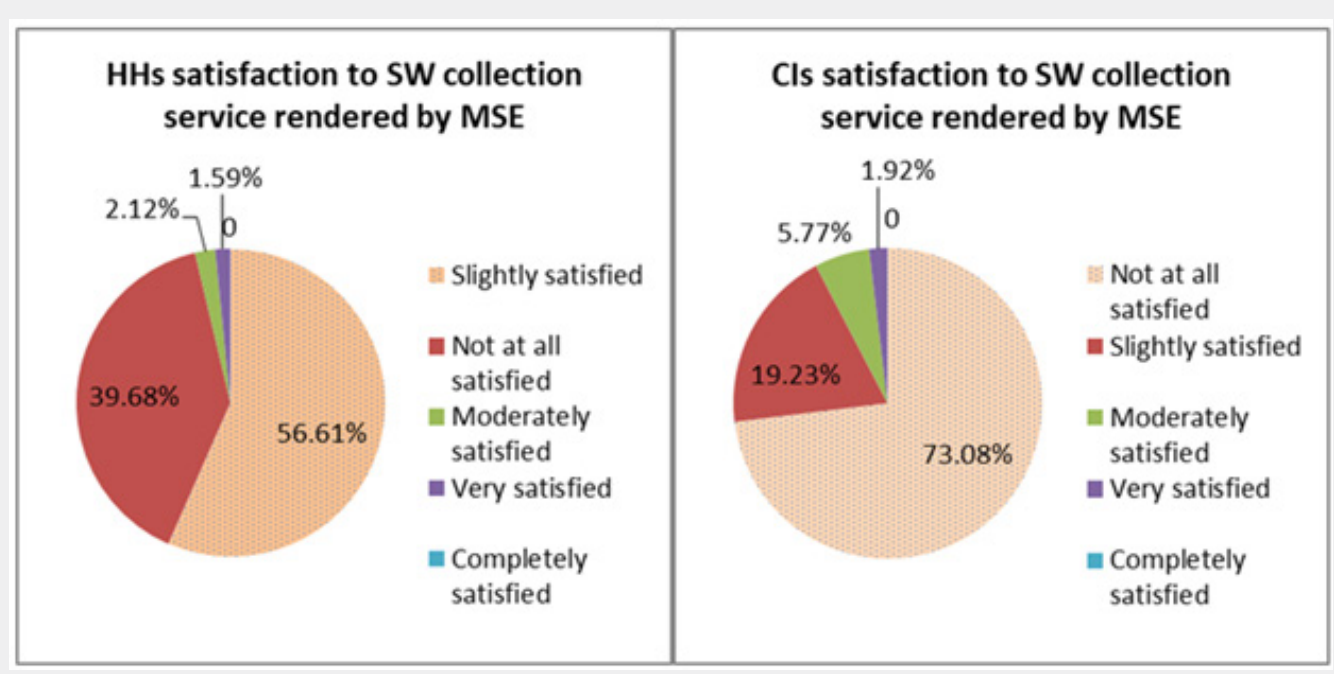

Figure 6: Client satisfaction to solid waste collection and management service rendered by MSE.

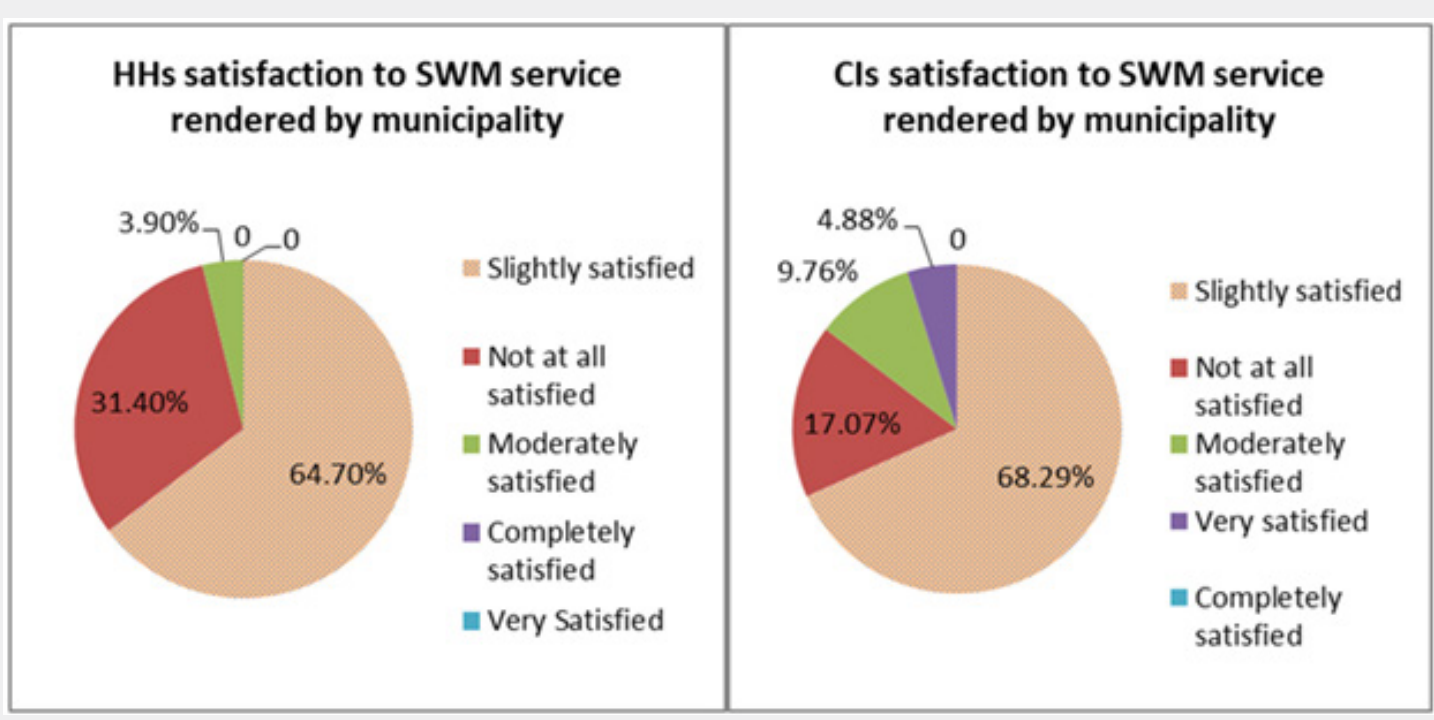

Figure 7: Client satisfaction to solid waste collection and management service rendered by municipality.

Regarding MSE service, costumers were asked about their satisfaction level, $56.61 \%$ of $\mathrm{HHs}$ and $19.23 \%$ of CIs were responded that they were slightly satisfied. Whereas, $39.68 \%$ of HHs and $73.08 \%$ of CIs responded that they were not at all satisfied. Besides this study has tried evaluating customer's satisfaction toward the solid waste management service rendered by the municipality. Accordingly, about $64.7 \%$ of HHs and $68.29 \%$ of CIs responded that they were slightly satisfied. Whereas, about $31.4 \%$ HHs and $17.04 \%$ of CIs responded that they were not at all satisfied. Only, about $5.77 \%$ and $9.76 \%$ of CIs responded that they were moderately satisfied with both MSE and municipal service, respectively. None of the customers responded that they are completely satisfied with both municipal and MSE services.

Sustainable solid waste management relies on the attitude and practice of the community, the commitment of the local administration body, the participation of formal and informal sectors with economic benefit. Outsourcing SWM service should 
be prior importance in developing countries like Ethiopia, in which the government body is busy dealing with huge social service issues. To overcome the underlying problems, the municipality should make the solid waste management of the town integrated in the way that it will contribute to the economic development of the community. Also, formalizing informal waste collectors and giving appropriate recognition will ensure better efficiency of SWM in the town by increasing their participation. Meanwhile, it can create a job for youth who are thirst for work as the unemployment rate in Ethiopia is $19.1 \%$ in 2018 [19]. The local administration body should build internal organizational capacity/skills and strengthen the pro-poor involvement in waste management as a source of employment and income generation in line with environmentally friendly waste management requirements.

\section{Conclusion}

In this study, it was tried to show the service delivery issues such as access to solid waste collection service, frequency of waste collection, the fee paid for the service, waste disposal site management, door to door waste collection coverage, the existing waste collection, and transportation status, and satisfaction level of the residents of Metu town. Accordingly, the main customerrelated problem identified was low access to door-to-door solid waste collection, irregular, and low solid waste collection frequency and illegal waste dumping. In another way, shortage of budget and facility (communal container and functional vehicle) for the service, poor administration (unwillingness to maintain the nonfunctional trucks and to allocate a separate budget for the service) and poor solid waste disposal site sitting and management were reported among the key challenges of solid waste management service giving body (municipality) in this study. In general, to build an acceptable and satisfactory level of MSWM service, the town municipality need to have well-organized management that functions within an adequate institutional arrangement, skilled manpower and financial resources, appropriate rule and regulation, short and long term strategy, and good cooperation with different stakeholders.

\section{Acknowledgement}

The authors are grateful to Metu Town municipality for their cooperation in this study and the Ethiopian Environment and Forest Research Institute for financial support. In addition, we would like to thank data collectors and study participants.

\section{References}

1. Chalmin P, Gaillochet C (2009) From waste to resource, An abstract of world waste survey, Cyclope, Veolia Environmental Services, Edition Economica, France.
2. Chandak SP (2010) Trends in Solid Waste Management - Issues, Challenges, and Opportunities presented at the International Consultative Meeting on Expanding Waste Management Services in Developing Countries, 18-19 March 2010, Tokyo, Japan.

3. Madinah N (2016) Solid Waste Management System: Public-Private Partnership, the Best System for Developing Countries. Int Journal of Engineering Research and Applications 6(4): 57-67.

4. Modak P, Jiemian Y, Hongyuan Y, Mohanty CR (2010) Shanghai Manual - A Guide for Sustainable Urban Development in the 21st Century. Chapter 5 -Municipal Solid Waste Management: Turning Waste in to Resources.

5. Le Courtois A (2013) Municipal Solid Waste: turning a problem into resource. In: Waste the challenges facing developing countries.

6. Bhanda-Tata H (2012) What a Waste: A Global Review of Solid Waste Management. Washington D.C. World Bank. Urban Development \& Local Government Unit.

7. Schertenleib R, Meyer W (1992) Municipal solid waste management in DC's: Problems and issues; need for future research. IRCWD News (No. 26), Duebendorf, Switzerland.

8. UNEP (2002) International Source Book on Environmentally Sound Technologies for Municipal Solid Waste Management, (IETC) Technical Publication no. 6.

9. Kassahun T, Birara E (2018) Assessment of Solid Waste Management Practices in Bahir Dar City, Ethiopia. J Pollution 4(2): 251-261.

10. Birhanu Y, Berisa G (2015) Assessment of Solid Waste Management Practices and the Role of Public Participation in Jigjiga Town, Somali Regional State, Ethiopia. International Journal of Environmental Protection and Policy 3(5): 153-168.

11. Hailemariam M, Ajeme A (2014) Solid Waste Management in Adama, Ethiopia: Aspects and Challenges. International Journal of Environmental, Ecological, Geological and Mining Engineering 8(9): 603-609.

12. Lema A (2007) Household solid waste generation rate and composition analysis in two selected kebles of Adama town. MSc thesis paper, Addis Ababa University. Addis Ababa, Ethiopia.

13. Lemma E, Tekilu H (2014) Characterization and Disposal of Municipal Solid Waste, Case Study, Hosanna Town. American Journal of Environmental Engineering 4(6): 162-168.

14. Diriba D (2009) Household Solid waste generation rate, Composition and content analysis for disposal and resource recovery in two selected kebeles of Hawassa Town. Master Thesis School of Graduate Studies of Addis University, Ethiopia, pp. 28-92.

15. Getahun T, Mengistie E, Haddis A, Wasie F, Alemayehu E, et al. (2012) Municipal solid waste generation in growing urban areas in Africa: current practices and relation to socioeconomic factors in Jimma, Ethiopia. Environ Monit Assess 184(10): 6337-6345.

16. Tadesse T, Ruijs A, Hagos FG (2007) Household waste disposal in Mekelle city, Northern Ethiopia. Waste Management 28(10): 2003-2012.

17. Gedefaw M (2015) Assessing the Current Status Of Solid Waste Management of Gondar town, Ethiopia. International Journal of Scientific Technology and Research 4(9): 28-36.

18. Cunningham $T$ (2008) Principles of Environmental Science Inquiry and Applications. (4th edn), USA: McGraw Hill International Edition.

19. Trading Economics (2020) Ethiopian Unemployment rate. 
(C) Commons Attribution 4.0 License

(C) DOI:10.19080/IJESNR.2020.25.556166
Your next submission with Juniper Publishers will reach you the below assets

- Quality Editorial service

- Swift Peer Review

- Reprints availability

- E-prints Service

- Manuscript Podcast for convenient understanding

- Global attainment for your research

- Manuscript accessibility in different formats ( Pdf, E-pub, Full Text, Audio)

- Unceasing customer service

Track the below URL for one-step submission https://juniperpublishers.com/online-submission.php 